\title{
Loneliness or Materialism, Which Is a Better Predictor of Internet Addiction?
}

\author{
Srikant Manchiraju \\ Jim Moran School of Entrepreneurship, Florida State University, Tallahassee, USA \\ Email: Smanchiraju@fsu.edu
}

How to cite this paper: Manchiraju, S. (2018) Loneliness or Materialism, Which Is a Better Predictor of Internet Addiction? Social Networking, 7, 137-146. https://doi.org/10.4236/sn.2018.73011

Received: March 27, 2018

Accepted: July 15, 2018

Published: July 18, 2018

Copyright (C) 2018 by author and Scientific Research Publishing Inc. This work is licensed under the Creative Commons Attribution International License (CC BY 4.0).

http://creativecommons.org/licenses/by/4.0/

\begin{abstract}
In recent years, the widespread prevalence of loneliness, materialism, and Internet addiction have been widely studied. Studies have addressed either loneliness or materialism and its relationship with Internet addiction. However, to date, no study has addressed all three concepts in a single study. The purpose of this study was: 1 ) to investigate whether loneliness or materialism is a reliable predictor of Internet addiction and 2) what is the nature of the relationship among these variables across gender. Data were collected from a crosssectional online-survey, which consisted of US adults $(\mathrm{N}=311)$. The survey consisted of 42 items related to the key constructs. Additionally, some demographic variables were also included in the survey. Loneliness was not associated with Internet addiction. On the other hand, materialism was strongly associated with Internet addiction. The aforementioned relationship was valid across gender. Between loneliness and materialism, materialism was a strong predictor of Internet addiction.
\end{abstract}

\section{Keywords}

Loneliness, Materialism, Internet Addiction

\section{Introduction}

The $21^{\text {st }}$ century is replete with epidemics. However, loneliness, materialism, and Internet addiction have received considerable attention. The aforementioned epidemics have been reported to have negative implications both for the individual as well as the society in general. For instance, loneliness has been associated with physical (e.g., diabetes) and psychological disorders (e.g., anxiety) ([1]). Likewise, materialism has been associated with psychological disorders (e.g., anxiety and substance abuse; [2] [3]). And, certainly, with advent of technological progress, the concept of Internet addiction and its negative conse- 
quences have been noted extensively in recent years (e.g., [4]). All-loneliness, materialism, and Internet addiction are on the rise in modern society. Literature from diverse disciplines, which include marketing (e.g., [3]), social psychology (e.g., [5]), and abnormal psychology among others have noted the rise of these epidemics in recent years. For instance, Christakis and Moreno [6] have labelled Internet addiction as a $21^{\text {st }}$-century epidemic, with high prevalence rates across the world. For instance, 1 in 8 US adults is considered to be an Internet addict, noted Christakis and Moreno [6]. Likewise, the numbers related to loneliness and materialism are staggering. Although no formal diagnosis is in place for these concepts, as per Diagnostic and Statistical Manual of Mental Disorders ( $5^{\text {th }}$ Edition), most researcher agree that these are problematic issues that have to be addressed.

Consequently, the purpose of the present study is to investigate the relationships between these three concepts. More specifically, is it loneliness or individual materialism that best predicts Internet addiction? Furthermore, how do these concepts vary across gender? By addressing these questions, the researcher hopes to initiate a constructive dialogue that might have wide ranging implicationsfrom development of non-pharmacologically addictive behavior intervention, to broad public policy implications.

\subsection{Conceptualizing Internet Addiction}

Internet addiction can be described as a disorder in which the individual's inability to control one's use of the Internet causes marked distress and/or functional impairment ([7]). The dominant view towards the disorder is that it is a "behavioral addiction." Behavioral addiction refers to non-substance addiction, which is has similar features as drug addiction (e.g., withdrawal, craving, etc.) ([8]). It should be noted that several competing views exists on Internet addiction. However, for the purpose of the present study, Internet addiction is viewed as an impulsivity disorder. For other perspectives, literature can be found elsewhere (e.g., [7] [9] [10]).

\subsection{Internet Addiction and Loneliness}

Loneliness refers to subjective painful experience, which might be due to absence of social contact, belongingness, or a sense of isolation ([1]). Given that loneliness is pervasive phenomenon, research focusing on the topic has exponentially increased in the past two decades, noted Mushtaq, Shoib, Shah, and Mushtaq [11]. For example, loneliness is experienced by $80 \%$ of population below 18 years of age, and $40 \%$ of the population above 65 years of age report experiencing loneliness at least sometimes in their life ([11]). Studies (e.g., [1] [11] [12]) have noted the negative implications of loneliness for the individual and the society in general. For example, Beutel et al. [1] found that loneliness was associated with host of mental issues, which included depression, anxiety, and suicide ideation. They further reported that lonely individuals were more likely to smoke often 
and are susceptible to frequent doctor visits. In similar vein, Mushtaq et al. [11] maintained that loneliness can cause serious health problems that includes physical disorders (e.g., diabetes), autoimmune disorders (e.g., rheumatoid arthritis), cardiovascular diseases (e.g., coronary heart disease), and poor hearing, among others.

Research (e.g., [13] [14] [15] [16]) has been conducted that explored the relationship between Internet addiction and loneliness. For instance, Pontes et al. [15] found that loneliness among children and adolescent was one of the predictors of Internet addiction. Similar findings have been reported by Demir and Kutlu [13]. They noted that among 17 to 31 years old university students, loneliness was a strong predictor of Internet addiction. Pala and Biner [14] found that among Turkish university students, loneliness was more pervasive among individuals who were Internet addicts. All in all, considering the aforementioned discussion, it is clear that there is a positive relationship between loneliness and Internet addiction. Based on the literature reviewed, the following hypothesis is proposed:

$H 1$ : Loneliness is positively associated with Internet addiction.

\subsection{Internet Addiction and Materialism}

Materialism is defined as, "the importance a consumer attaches to worldly possessions" ([17], 291). In other words, in common usage, materialism is associated with the tendency to consider material possessions and physical comfort as more important than spiritual values ([3]). Due to globalization, individual level of materialism is on the rise ([18]). Myers [19] mentioned a study conducted by the UCLA/American Council of Education that surveyed a quarter million collegians; the proportion of individuals who expressed financial success as very important to them grew from 39 percent in 1970 to 78 percent in 2009 . Like loneliness, several negative consequences of materialism have been noted (e.g., [3] [20]). For instance, risk-taking behavior and ethical lapses are common among materialistic CEOs ([21]). In general, it has been found that materialism is negatively associated with one's wellbeing, which is based on a recent meta-analytic study that consisted of 259 independent samples ([22]). Likewise, materialism has been commonly associated with psychological disorders such as anxiety and depression ([2]), compulsive buying ([23]), and risky health behaviors such as smoking cigarettes, drinking alcohol, and using drugs ([22]). Furthermore, materialism and loneliness have been considered to be associated with each other (e.g., [24] [25]). For instance, Pieters [25] noted that materialism and loneliness tend to influence each other in a downward spiral mode.

Some research has addressed the relationship between behavioral addiction and materialism (e.g., [26] [27] [28]). For example, Roberts et al. [27] found that materialism positively predicted-smartphone addiction, which is similar to Internet addiction ([26]). Also, other studies have noted the role of materialism in the context of Internet addiction (e.g., [29]). It has been posited that further ex- 
ploration between materialism and Internet addiction is warranted ([26]). Therefore, based on limited literature, the following hypothesis is proposed:

$H 2$ : Materialism is positively associated with Internet addiction.

\section{Methods}

The present study was designed in the form of a cross-sectional survey. The participants of the study were recruited via a US-based market research firm. All the participants were based in the US, who were 18 years or older. Institutional Review Board approval on human subjects was obtained prior to collecting the data. Each participant was given a nominal financial incentive. Data were collected over a one-week period.

\subsection{Questionnaire}

The survey consisted of 7-point Likert-type scales $(1=$ Strongly Disagree, $7=$ Strongly Agree) measuring all the research variables. Thus, the survey included-13 items measuring Internet addiction (IA) ([30]), a 9-item scale measuring materialism ([31]), and 20-item scale measuring loneliness ([5]). Cronbach's alpha reliabilities for the employed scales were reported to be .70 or higher. Additionally, the survey consisted of demographic items such gender and income.

\subsection{Data Analysis}

A variety of quantitative statistical techniques were employed in the analysis of survey data through SPSS 22.0 and Mplus 6.0 programs. First, descriptive analyses were performed on participants' demographic characteristics. Second, Cronbach's alpha coefficients of the scales employed were calculated. Finally, Mplus 6.0 was used to conduct confirmatory factor analysis (CFA) and structural equation modeling (SEM) were conducted to test the proposed research model (see Figure 1). Furthermore, a post-hoc multi-group SEM was conducted to explore the data further.

\section{Results}

A total of 311 useable complete responses were collected. The majority of the respondents were female (71\%), white (82\%), and with household income less than $\$ 50,000$ (58\%) (see Table 1 for demographic characteristics of the sample). Thirty-nine percent of the respondents bought something online at least 1 to 5 times, $21 \%$ bought something online at least 6 to 10 times, and $16 \%$ bought something online over 20 times in the past 12 months. The majority of the respondents (51\%) spend more than three hours per day on the Internet.

The Cronbach's alpha for all constructs were above the threshold of .70, which satisfied the required internal consistency. Next, CFA was conducted, which included three latent variables and 42 indicators that were parceled (see [32]). The CFA resulted in a good model fit $\left(\chi^{2}=71.25, d f=23, p<0.001\right.$, CFI $=0.97$, TLI 


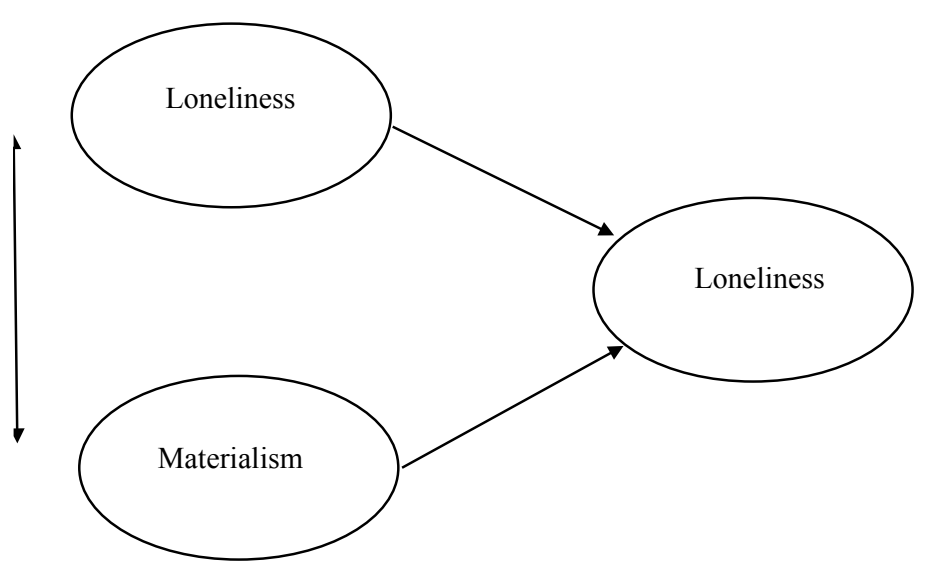

Figure 1. The proposed research model.

Table 1. Characteristics of the sample $(n=311)$.

\begin{tabular}{|c|c|}
\hline Demographics & $\%$ \\
\hline \multicolumn{2}{|c|}{ Gender } \\
\hline Male & 29 \\
\hline Female & 71 \\
\hline \multicolumn{2}{|c|}{ Ethnicity } \\
\hline White & 82 \\
\hline Hispanic or Latino & 4 \\
\hline Black or African American & 11 \\
\hline Asian or Pacific Islander & 1 \\
\hline Other & 2 \\
\hline \multicolumn{2}{|l|}{ Age } \\
\hline $18-24$ & 3 \\
\hline $25-34$ & 9 \\
\hline $35-44$ & 15 \\
\hline $45-54$ & 20 \\
\hline $55-64$ & 22 \\
\hline $65-74$ & 25 \\
\hline$>75$ & 6 \\
\hline \multicolumn{2}{|l|}{ Education } \\
\hline High school degree & 34 \\
\hline Associate degree & 23 \\
\hline Bachelor's degree & 24 \\
\hline Master's degree & 7 \\
\hline Professional or doctorate degree & 2 \\
\hline Other & 10 \\
\hline \multicolumn{2}{|c|}{ Income } \\
\hline$<\$ 50,000$ & 58 \\
\hline$\$ 50,000-\$ 100,000$ & 24 \\
\hline$\$ 100,001-\$ 150,000$ & 12 \\
\hline$\$ 150,001-\$ 200,000$ & 4 \\
\hline$>200,000$ & 2 \\
\hline
\end{tabular}


$=0.95$, RMSEA $=0.08$, SRMR $=0.05)$.

Subsequent structural model was run to test the hypothesized relationships. The SEM resulted in a good model fit $\left(\chi^{2}=71.25, d f=23, p<0.001, \mathrm{CFI}=0.96\right.$, TLI $=0.95$, RMSEA $=0.08$, SRMR $=0.05)$. Based on standardized path coefficients and significance levels, Loneliness was not associated with Internet addiction (beta $=0.073, p=0.187$ ). Although the magnitude of the beta coefficient was in the expected direction, the statistical significance failed at $p<0.05$ level. In other words, $H 1$ was not supported. On the other hand, materialism was positively and significantly associated with Internet addiction (beta $=0.603, p<$ $0.001)$. Therefore, H2 was supported. Furthermore, consistent with the literature, materialism and loneliness were positively correlated $(\mathrm{r}=0.19, p=0.005)$. In total, the hypothesized model explained $38.5 \%$ of variance in Internet addiction $(\mathrm{R}-\mathrm{sq}=0.385, p<0.001)$. See Figure 2 for results.

To further explore the data collected, additional analyses were conducted. More specifically, a two-group SEM based on participant's gender $\left(\mathrm{N}_{\text {Male }}=90\right)$ was conducted. The rationale being that the key constructs involved in the study have been found to vary across gender (e.g., [33]). However, consistent with the overall model, even across gender, loneliness wasn't associated with Internet addiction $\left(\right.$ beta $_{\text {Male }}=0.10, p=0.295$ beta $\left._{\text {Female }}=0.021, p=0.765\right)$. Also, materialism was positively associated with Internet addiction for both genders $\left(\right.$ beta $_{\text {Male }}=$ $0.74, p<0.001$; beta $_{\mathrm{Female}}=0.563, p<0.001$ ). Interestingly, the association between materialism and Internet addiction was stronger among men than women. The research model explained $59.2 \%$ and $32.1 \%$ of variance in Internet addiction for males and females respectively $\left(\mathrm{R}-\mathrm{sq}_{\mathrm{Male}}=0.592, p<0.001 ; \mathrm{R}-\mathrm{sq}_{\mathrm{Female}}\right.$ $=0.321, p<0.001)$. Also, the correlations between loneliness and materialism were.18 $(p=0.025)$ and $0.23(p=0.06)$ for males and females respectively.

\section{Discussion}

The main purpose of the present study was to investigate the phenomena of

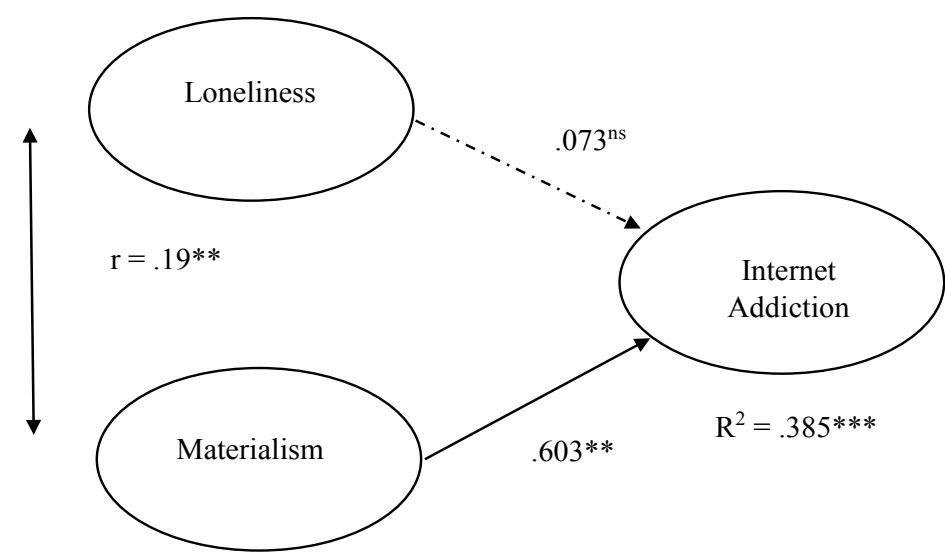

Figure 2. The standardized path coefficients (Fit: $\chi^{2}=71.25, d f=23, p<$ 0.001 , CFI $=0.96$, TLI $=0.95$, RMSEA $=0.08$, SRMR $=0.05)$. Note, ns: non-significant; ${ }^{\star *} p<0.005 ;{ }^{* *} p<0.0001$. 
loneliness, materialism, and Internet addiction. More specifically, to see the associations between loneliness and materialism with Internet addiction. Previous studies (e.g., [29]) have investigated the link between either loneliness or materialism and their association with Internet addiction. However, to date, to the researcher's knowledge, no study has been conducted that takes both-loneliness and materialism in to consideration to predict Internet addiction. From the findings of the present study, it is clear that materialism is a stronger predictor of Internet addiction. One rationale being that Internet addiction causes loneliness, not the other way around, noted Morahan-Martin [34]. However, the empirical study with regards to loners and Internet addiction directionality is not conclusive and warrants further investigation. However, from the present study it is evident that loneliness is not a valid predictor of Internet addiction. On the other hand, Chou, Condron, and Belland [4] noted that low self-esteem, fear of rejection, and need for approval drive Internet addiction. Surprisingly, the aforementioned concepts have also been associated with individual's level of materialism. In other words, these concepts are more strongly associated with Internet addicts as well as materialists, perhaps, not shared so much by loners. Future research in this direction is warranted.

Also, when considered in conjunction (i.e., loneliness and materialism), materialism but not loneliness is a significant predictor of Internet addiction. The aforementioned relationship is stronger among men than women. This finding is consistent with the notion that Internet addiction is more prevalent among men than women (e.g., [4]). Similarly, Morahan-Martin and Schumacker [30] reported that men were more likely to be Internet addicts than women ( $12 \% \mathrm{vs}$. $3 \%)$. The rationale being that men seek dominant activities or contents online (e.g., online games) or sexual fantasies in cyberspace more often on the Internet than women, noted Young [10].

\section{Study Limitations and Future Directions}

The study in question has few shortcomings. The present study was cross-sectional in nature. Therefore, the exploration of the nature of relationship between the research variables is not causal. The study only points to the nature of the relationship. For a causal inference, future studies should conduct longitudinal studies, or even experimental studies (e.g., priming). Furthermore, the study was based on self-report scores as well as its cross-sectional design makes it susceptible to common method bias ([35]). The study focused on specific geographic location (i.e., the US). Hence, generalization of the present study cannot be made. Thus, future studies should investigate diverse geographic locations and cultures. As noted above, the researcher encourages more research in this area to draw any strong conclusions.

\section{References}

[1] Beutel, M.E., Klein, E.M., Brähler, E., Reiner, I., Jünger, C., Michal, M., Tibubos, 
A.N., et al. (2017) Loneliness in the General Population: Prevalence, Determinants and Relations to Mental Health. BMC Psychiatry, 17, 97. https://doi.org/10.1186/s12888-017-1262-X

[2] Kasser, T. (2002) The High Price of Materialism. MIT Press, Cambridge.

[3] Manchiraju, S. (2013) Materialism in Consumer Behavior and Marketing: A Review. Management \& Marketing, 8, 329-351.

[4] Chou, C., Condron, L. and Belland, J.C. (2005) A Review of the Research on Internet Addiction. Educational Psychology Review, 17, 363-388.

https://doi.org/10.1007/s10648-005-8138-1

[5] Russell, D.W. (1996) UCLA Loneliness Scale (Version 3): Reliability, Validity, and Factor Structure. Journal of Personality Assessment, 66, 20-40. https://doi.org/10.1207/s15327752jpa6601_2

[6] Christakis, D.A. and Moreno, M.A. (2009) Trapped in the Net: Will Internet Addiction Become a 21st-Century Epidemic? Archives of Pediatrics \& Adolescent Medicine, 163, 959-960. https://doi.org/10.1001/archpediatrics.2009.162

[7] Burnay, J., Billieux, J., Blairy, S. and Larøi, F. (2015). Which Psychological Factors Influence Internet Addiction? Evidence through an Integrative Model. Computers in Human Behavior, 43, 28-34. https://doi.org/10.1016/j.chb.2014.10.039

[8] Block, J.J. (2008) Issues for DSM-V: Internet Addiction.

[9] Griffiths, M.D., Kuss, D.J., Billieux, J. and Pontes, H.M. (2016) The Evolution of Internet Addiction: A Global Perspective. Addictive Behaviors, 53, 193-195. https://doi.org/10.1016/j.addbeh.2015.11.001

[10] Young, K.S. (1998) Internet Addiction: The Emergence of a New Clinical Disorder. Cyberpsychology \& Behavior, 1, 237-244. https://doi.org/10.1089/cpb.1998.1.237

[11] Mushtaq, R., Shoib, S., Shah, T. and Mushtaq, S. (2014) Relationship between Loneliness, Psychiatric Disorders and Physical Health? A Review on the Psychological Aspects of Loneliness. Journal of Clinical and Diagnostic Research: JCDR, 8, WE01.

[12] Pittman, M. and Reich, B. (2016) Social Media and Loneliness: Why an Instagram Picture May Be Worth More than a Thousand Twitter Words. Computers in Human Behavior, 62, 155-167. https://doi.org/10.1016/j.chb.2016.03.084

[13] Demir, Y. and Kutlu, M. (2016) The Relationship between Loneliness and Depression \& 58; Mediation Role of Internet Addiction. Educational Process: International Journal, 5, 97-105. https://doi.org/10.12973/edupij.2016.52.1

[14] Pala, A. and Biner, M. (2016) Technological Loneliness; the Effect on Loneliness of Internet Addiction of University Students; the Case of Turkey. World Academy of Science, Engineering and Technology, International Journal of Humanities and Social Sciences, 3.

[15] Pontes, H.M., Griffiths, M.D. and Patrão, I.M. (2014) Internet Addiction and Loneliness among Children and Adolescents in the Education Setting: An Empirical Pilot Study. Aloma: Revista de Psicologia, Ciències de l Educació $i$ de P Esport, 32.

[16] Yao, M.Z. and Zhong, Z.J. (2014) Loneliness, Social Contacts and Internet Addiction: A Cross-Lagged Panel Study. Computers in Human Behavior, 30, 164-170. https://doi.org/10.1016/j.chb.2013.08.007

[17] Belk, R.W. (1984) Three Scales to Measure Constructs Related to Materialism: Reliability, Validity, and Relationships to Measures of Happiness. Advances in Consumer Research, 11, 291-297.

[18] Lim, M.W., Ting, D.H., Khoo, P.T. and Wong, W.Y. (2012) Understanding Consumer Values and Socialization-A Case of Luxury Products. Management and 
Marketing Challenges for the Knowledge Society, 7, 209-220.

[19] Myers, D. (2012) Exploring Social Psychology. McGraw Hill, New York.

[20] Shrum, L.J., Wong, N., Arif, F., Chugani, S.K., Gunz, A., Lowrey, T.M., Scott, K., et al. (2013) Reconceptualizing Materialism as Identity Goal Pursuits: Functions, Processes, and Consequences. Journal of Business Research, 66, 1179-1185. https://doi.org/10.1016/j.jbusres.2012.08.010

[21] Bushman, R.M., Davidson, R.H., Dey, A. and Smith, A.J. (2017) Bank CEO Materialism: Risk Controls, Culture and Tail Risk.

[22] Dittmar, H., Bond, R., Hurst, M. and Kasser, T. (2014) The Relationship between Materialism and Personal Well-Being: A Meta-Analysis. Journal of Personality and Social Psychology, 107, 879-924. https://doi.org/10.1037/a0037409

[23] Manolis, C. and Roberts, J.A. (2012) Subjective Well-Being among Adolescent Consumers: The Effects of Materialism, Compulsive Buying, and Time Affluence. Applied Research in Quality of Life, 7, 117-135. https://doi.org/10.1007/s11482-011-9155-5

[24] Ang, C.S., Mansor, A.T. and Tan, K.A. (2014) Pangs of Loneliness Breed Material Lifestyle But Don't Power up Life Satisfaction of Young People: The Moderating Effect of Gender. Social Indicators Research, 117, 353-365. https://doi.org/10.1007/s11205-013-0349-0

[25] Pieters, R. (2013) Bidirectional Dynamics of Materialism and Loneliness: Not Just a Vicious Cycle. Journal of Consumer Research, 40, 615-631. https://doi.org/10.1086/671564

[26] Lee, Y.K., Chang, C.T., Cheng, Z.H. and Lin, Y. (2018) How Social Anxiety and Reduced Self-Efficacy Induce Smartphone Addiction in Materialistic People. Social Science Computer Review, 36, 36-56. https://doi.org/10.1177/0894439316685540

[27] Roberts, J.A., Pullig, C. and Manolis, C. (2015) I Need My Smartphone: A Hierarchical Model of Personality and Cell-Phone Addiction. Personality and Individual Differences, 79, 13-19. https://doi.org/10.1016/j.paid.2015.01.049

[28] Sharif, S.P. and Khanekharab, J. (2017) Identity Confusion and Materialism Mediate the Relationship between Excessive Social Network Site Usage and Online Compulsive Buying. Cyberpsychology, Behavior, and Social Networking, 20, 494-500. https://doi.org/10.1089/cyber.2017.0162

[29] Roberts, J.A. and Pirog III, S.F. (2012) A Preliminary Investigation of Materialism and Impulsiveness as Predictors of Technological Addictions among Young Adults. Journal of Behavioral Addictions, 2, 56-62. https://doi.org/10.1556/JBA.1.2012.011

[30] Morahan-Martin, J. and Schumacher, P. (2000) Incidence and Correlates of Pathological Internet Use among College Students. Computers in Human Behavior, 16, 13-29. https://doi.org/10.1016/S0747-5632(99)00049-7

[31] Richins, M.L. (2004) The Material Values Scale: Measurement Properties and Development of a Short Form. Journal of Consumer Research, 31, 209-219. https://doi.org/10.1086/383436

[32] Little, T.D., Cunningham, W.A., Shahar, G. and Widaman, K.F. (2002) To Parcel or Not to Parcel: Exploring the Question, Weighing the Merits. Structural Equation Modeling, 9, 151-173. https://doi.org/10.1207/S15328007SEM0902_1

[33] Yen, J.Y., Yen, C.F., Chen, C.S., Tang, T.C. and Ko, C. (2009) The Association between Adult ADHD Symptoms and Internet Addiction among College Students: The Gender Difference. Cyberpsychology \& Behavior, 12, 187-191. https://doi.org/10.1089/cpb.2008.0113 
[34] Morahan-Martin, J. (1999) The Relationship between Loneliness and Internet Use and Abuse. CyberPsychology \& Behavior, 2, 431-439.

https://doi.org/10.1089/cpb.1999.2.431

[35] Podsakoff, P.M., MacKenzie, S.B., Lee, J.Y. and Podsakoff, N.P. (2003) Common Method Biases in Behavioral Research: A Critical Review of the Literature and Recommended Remedies. Journal of Applied Psychology, 88, 879-903.

https://doi.org/10.1037/0021-9010.88.5.879 